\title{
Evidence based health promotion: recollections, reflections, and reconsiderations
}

\author{
K C Tang, J P Ehsani, D V McQueen
}

J Epidemiol Community Health 2003;57:841-843

l: mproving the evidence base of health promotion is high on the agenda of the international health promotion community and it is becoming increasingly apparent that evidence is needed by practitioners for effective health promotion interventions. It is generally accepted that with quality findings from intervention studies, practitioners can make better decisions to achieve effectiveness in their interventions. Moreover, without evidence of effective health promotion, it may be difficult to obtain policy support.

Over the past few years, the debate on the concept or nature of evidence in health promotion effectiveness and its appraisal has focused on the design of a study and other related methodological issues such as validity of indicators, efficacy of the intervention, and context in which the intervention operates. ${ }^{1-4}$ To a great extent the quality of the evidence has been determined by using the hierarchical structure established by those working in evidence based medicine $^{5}$ adopting a positivist paradigm.

\section{THE RULES OF THE NATURAL SCIENCES}

To this end, emphasis has been placed on achieving the three rules of scientific inquiry: predictability, repeatability, and falsifiability, when determining the strength of evidence. These are based on widely recognised principles stemming from discussions in the philosophy of science. Predictability is said to be met when a properly implemented intervention will bring about an expected outcome, given that the key elements of the intervention and the cause-effect interaction among those elements are known. The elements of the intervention and the causal relations of those elements thus need to be specified. Repeatability, sometimes referred to as replicability, refers to universal application of the intervention, regardless of time and place. The intervention is therefore required to yield the same result wherever and whenever it is carried out. To be falsifiable, the intervention must be capable of being disproved as an effective intervention. Once implemented, the intervention is validated if rigorous evaluation research demonstrates that it works and is falsified if it is shown to be ineffective or harmful.

Health promotion operates in an environment where numerous cultural, social, economic, and political factors interact. Given a complex context where the links among the elements of an intervention are interrelated, causality, more often than not, cannot be directly established. It is indeed difficult to define causality in a succinct manner. ${ }^{67}$ In brief, it refers to, in biomedical sciences, a probabilistic notion that if an " $\mathrm{x}$ " (the exposure) precedes a " $\mathrm{y}$ " (the effect) and there is a statistical association between " $\mathrm{x}$ " and " $\mathrm{y}$ " and if a reduction of " $\mathrm{x}$ " will lead to a reduction of " $\mathrm{y}$ " and there is not a " $\mathrm{Z}$ " confounding the association, then causation is imputed. Repeatability of an intervention, regardless of time and place, also has proved difficult to be achieved. The application of the rules of science to health promotion is therefore of questionable merit.
It is also important to note that a large part of health promotion is of a social science nature. Behavioural and policy changes are two key focal concerns of many health promotion activities and behaviour is structured by society or is socially constructed. Behaviour here refers to that of individuals as well as of organisations and as such can include lifestyle practices and participation among people in the wider community, sales promotion behaviour of the private industries, and the predisposition of policy makers. Taking into consideration the various types of behaviour (or vested interests), the expressed needs of people in the wider community and the availability of resources, intervention activities as well as policy decisions are determined. When behaviour of individuals, organisations, or the political process is the focus, whether it relates to lifestyle practices, sales decisions or public policy formulation, the explanatory power of science will be limited. Above all, it may be problematic to fit these rules of the natural sciences to the social science disciplines. ${ }^{8}$

Although the finding of an intervention study may not constitute scientific fact as described by the criteria above, it can be a piece of evidence in the sense that it is a fact disclosed as a result of an evaluation process whereby methods of reasonable rigour are used. In health promotion, for an intervention to be effective, a combination of behavioural, social, and environmental strategies is used. For such interventions, it is not uncommon that the "what works" component is known but "how it works" component remains unclear. This allowance does not imply a compromise of accepted standards of methodological rigour in the development, implementation and evaluation of interventions. Rather, it expands the range and scope of what can be regarded as valid "evidence" and hence broadens the knowledge and experience base that practitioners and policy makers can draw from.

\section{TOWARDS AN IDEAL TYPOLOGY OF EVIDENCE}

One type of evidence can be found without meeting the causality criterion but where the different elements of an intervention work as a whole to produce the desired outcome. Interventions that may have limited repeatability-for example, only at the local level and within a certain period-can be classified as another type of evidence so long as the intervention works. In sum, a typology of evidence emerges, consisting of four classifications (table 1).

A. Evidence of implemented interventions that meet the criteria for scientific fact-that is, they are proved predictable, and repeatable, regardless of time and place. Assuming there is compliance, immunisation and condom use are classic examples of intervention where the elements of the intervention are known, the cause effect interaction is apparent and have universal application.

B. Evidence from interventions that produce desired outcomes and are predictable but are repeatable only at a local level within a certain period of time. The development of 
Table 1 The four classifications used in typology of evidence

\begin{tabular}{|c|c|c|c|c|}
\hline & A & B & C & D \\
\hline $\begin{array}{l}\text { What works: elements of } \\
\text { an intervention that work } \\
\text { (intervention demonstrated } \\
\text { to work in evaluation } \\
\text { research) }\end{array}$ & $\begin{array}{l}\text { What works is } \\
\text { Known }\end{array}$ & $\begin{array}{l}\text { What works is } \\
\text { Known }\end{array}$ & $\begin{array}{l}\text { What works is } \\
\text { Known }\end{array}$ & $\begin{array}{l}\text { What works is } \\
\text { Known }\end{array}$ \\
\hline $\begin{array}{l}\text { How it works: cause-effect } \\
\text { interaction among those } \\
\text { elements (the components } \\
\text { and how they work) }\end{array}$ & $\begin{array}{l}\text { How it works is } \\
\text { Known }\end{array}$ & $\begin{array}{l}\text { How it works is } \\
\text { Known }\end{array}$ & $\begin{array}{l}\text { How it works is } \\
\text { Not known }\end{array}$ & $\begin{array}{l}\text { How it works is } \\
\text { Not known }\end{array}$ \\
\hline Repeatability & $\begin{array}{l}\text { Repeatability is } \\
\text { Universal }\end{array}$ & $\begin{array}{l}\text { Repeatability is } \\
\text { Limited }\end{array}$ & $\begin{array}{l}\text { Repeatability is } \\
\text { Universal }\end{array}$ & $\begin{array}{l}\text { Repeatability is } \\
\text { Limited }\end{array}$ \\
\hline
\end{tabular}

assertiveness skills in commercial sex workers to encourage clients to use condoms, coupled with the availability of condoms, is an example of such an intervention where the cause-effect relation can be determined and the elements readily identified. However, the applicability of this intervention is limited to settings where the selling of sex is culturally acceptable and not otherwise.

C. Evidence from interventions that work as predicted to produce desired outcomes, without meeting the causality criterion, and are repeatable at any time and anywhere. Acupuncture is an example for treating some illness conditions such as pain relief.

D. Evidence from interventions that work as predicted, without meeting the causality criterion, and are repeatable only at a local level within a certain period of time. Community based trials to promote physical activity use a combination of behavioural, social, and environmental action areas which are effective, however which specific component of the action areas led to the outcome is unknown. The success may also be attributable to the interaction effect of the different types of action areas at work. Furthermore, the application is limited by the context where the intervention is applied; hence universal application cannot be achieved.

\section{STRENGTH AND TYPES OF EVIDENCE}

Thus far, the strength or hierarchy of evidence of an intervention is, in essence, determined by its evaluation design taking into consideration other methodological issues such as indicator validity and intervention efficacy. Yet the strength of a piece of evidence derived from an intervention may not be simply determined by evaluation design and related methodological issues. They are necessary but not sufficient. As illustrated above, there are four types of evidence and within each type, all the above mentioned methodological issues apply. Yet implicit in the typology, the strength of evidence of type A would seem to be superior to that of other types.

Even if an intervention is shown to work and the methods used to evaluate that intervention are sound, there are other dimensions that need to be certain, for example, how it works and whether or not it is repeatable.

The typology presented expands the dimension of evidence for health promotion interventions in the way that the typology presents a horizontal axis for the appraisal of evidence, opening new dimensions for practice and policy formulation and research.

\section{KNOWLEDGE BASED HEALTH PROMOTION}

For improving the evidence base of health promotion, in addition to the deliberation on the typology of evidence, there are other key concerns. In practice, it is important to note that evidence alone cannot constitute effective practice, as is the case of evidence based medicine. ${ }^{9}$ As suggested, external evidence can inform, but can never replace, the expertise of individual practitioners. It is this expertise that decides whether the external evidence is applied to the target group of an intervention at all and if so, how it should be used for achieving effectiveness. In other words, for an effective intervention, other critical areas in addition to evidence need to be taken into consideration-for example, the needs and expectations of direct service recipients, the interests of other key stakeholders, and the competency of a practitioner in planning and evaluation.

Conscientious and judicious use of evidence is only one competency element of health promotion. It is necessary but not sufficient for achieving effective health promotion. Health promotion practitioners are required to be able to absorb and use knowledge in many competency areas as specified in a review report. ${ }^{10}$

In policy formulation, while the strength of evidence is a base for policy development, there are also other considerations, for example, the socio-political and fiscal climate within which governments and organisations operate as well as the vested interests. The introduction of the typology will also give policy makers another dimension for consideration.

In research, effective health promotion often uses a combination of behavioural, social, and environmental strategies that work in synergy. The relation between the outcome variables and predictor variables are complex and not linear. The causal-effect relations of these variables cannot be addressed by traditional quantitative methods in public health alone. This necessitates new modes of practice to emerge and research methods in social sciences to be used, for example, the use of structured equation modelling to examine the validity of theoretical constructs and establish causal effects. The use of qualitative methods will help acquire a better understanding of the meaning of a concept and dissect the complexity of interactions. The use of qualitative methods may also be useful for achieving generalisability or transferability using the notion of representativeness in the concept when representativeness in the sample cannot be achieved. ${ }^{11}$

\section{ACKNOWLEDGEMENTS}

The authors wish to thank Dr Pekka Puska, Director, Department of Non-Communicable Disease Prevention and Health Promotion, World Health Organisation, for his comments on an earlier draft of the manuscript. 


\section{Authors' affiliations}

K C Tang, J P Ehsani, National and Community Programmes, Department of Non-Communicable Disease prevention and Health Promotion, WHO, Geneva

D V McQueen, National Center for Chronic Disease Prevention and Health Promotion, CDC, USA

Correspondence to: Dr K C Tang, National and Community Programmes, Department of Non-communicable Disease Prevention and Health Promotion, World Health Organisation, 20 Avenue Appia, CH1211 Geneva 27, Switzerland; tangkc@who.int

Accepted for publication 5 August 2003

\section{REFERENCES}

1 Raphael D. The question of evidence in health promotion. Health Promotion International 2000;15:355-67.
2 McQueen D. Strengthening the evidence base for health promotion. Health Promotion International 2001;16:261-8.

3 McQueen D. The evidence debate. J Epidemiol Community Health 2002;56:83-4.

4 Rychetnik L, Frommer M, Hawe $P$, et al. Criteria for evaluating evidence on public health interventions. J Epidemiol Community Health 2002;56:119-27.

5 Centre for Evidence-Based Medicine. Levels of evidence. http:// cebm.Jr2.ox.ac.uk/docs/levels.html (accessed Oct 2002).

6 Hill B. The environment and disease: association or causation? Proc $R$ Soc Med 1965:58:295-300.

7 Ehring D. Causation and persistence: a theory of causation. New York: Oxford University Press, 1997.

8 McQueen D. Perspectives on health promotion: theory, evidence, practice and the emergence of complexity. Health Promotion International 2000:15:95-7.

9 Sackett D, Rosenberg W, Gray J, et al. Evidenced-based medicine: What it is and what it isn't. BMJ 1996;312:71-2.

10 WHO SEARO. Review of certified education and training programmes for health promotion and education in the South East Asia region. New Delhi: WHO SEARO, 2002.

11 Strauss A, Corbin J. Basics of qualitative research: grounded theory procedures and techniques. California: Sage, 1990.

\section{THE JECH GALLERY}

Influential women in occupational health Victoire Cappe-for social justice

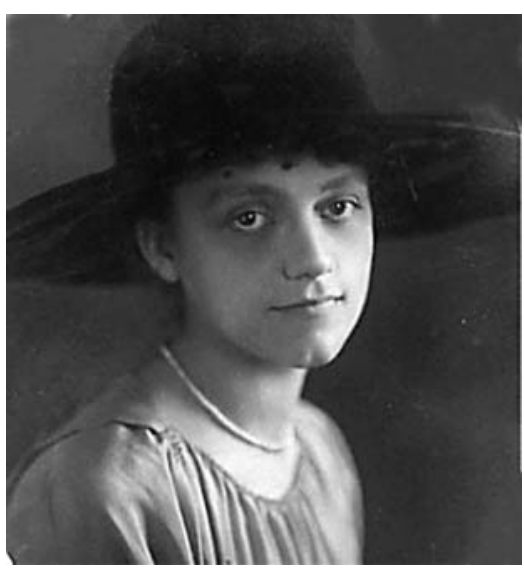

(photo courtesy of Leuven KADOC-Katholiek Documentatie, Katholieke Universiteit)

"...respect for the rights of working women and elevation of their dignity."
1886-1927

Country of birth: Belgium

$\sqrt{\text { inor }}$ ctoire Cappe taught social justice as a leader in the Christian Democratic labour movement. She was one of the founders of the Catholic school for social work.

In 1907, Cappe founded the Syndicat de l'Aiguille, the first union for needleworkers, dressmakers, and seamstresses. ${ }^{1}$ She also began study circles (monthly meetings for young girls and women) to overcome ignorance and indifference, and reach autonomy of mind and action.

Facing resistance from most of the clergy, but with the support of Cardinal Mercier, Cappe expanded unions to Brussels, then other Belgian cities. Later, she founded a national Christian professional women's union.

Although suffering with depression, she wrote a book (La Femme Belge), and edited monthly reviews, including a new journal, Joie et Travail.

Cappe attended the first Congress of the International Labor Organization in 1919 in Washington, DC, and the first international congress for women workers preceeding it. With Maria Baers and Isidore Maus, Cappe created the International Catholic Union of Social Work. Laboratories, Ann Arbor, MI, USA

I L Feitshans

Adjunct Faculty, Cornell University, School of Industrial and Labor Relations, Albany, NY, USA

Correspondence to: Deborah F Salerno, 2800 Plymouth Road, Ann Arbor, MI, USA; deborah.salerno@pfizer.com

\section{REFERENCE}

1 Keymolen D. Victoire Cappe 1886-1927. Une vie chrétienne, sociale, féministe, Leuven, Belgium: Presses Universitaires de Louvain, 2001. 